Supporting Information for

\title{
High-mobility flexible oxyselenide thin-film transistors prepared by solution-assisted method
}

Congcong Zhang ${ }^{\dagger}$, Jinxiong Wu ${ }^{\dagger, \star^{*},}$, Yuanwei Sun ${ }^{\S, \#}$, Congwei Tan ${ }^{\perp}$, Tianran $\mathrm{Li}^{\dagger}$, Teng Tư ${ }^{\dagger}$, Yichi Zhang ${ }^{\dagger}$, Yan Liang ${ }^{\dagger}$, Xuehan Zhou ${ }^{\dagger}$, Peng Gao ${ }^{\S}, \#$, Hailin Peng ${ }^{\dagger, *}$

${ }^{\dagger}$ Center for Nanochemistry, Beijing Science and Engineering Center for Nanocarbons, Beijing National Laboratory for Molecular Sciences, College of Chemistry and Molecular Engineering, Peking University, Beijing 100871, China

¥Tianjin Key Lab for Rare Earth Materials and Applications, Center for Rare Earth and Inorganic Functional Materials, School of Materials Science and Engineering, National Institute for Advanced Materials, Nankai University, Tianjin 300350, China

${ }^{\S}$ International Center for Quantum Materials, Electron Microscopy Laboratory, School of Physics, Peking University, Beijing 100871, China

${ }^{\#}$ Collaborative Innovation Center of Quantum Matter, Peking University, Beijing 100871, China

${ }^{\perp}$ Academy for Advanced Interdisciplinary Studies, Peking University, Beijing 100871, China

*To whom correspondence should be addressed.

Email:jxwu@nankai.edu.cn, hlpeng@pku.edu.cn. 


\section{Part-I: Methods}

\section{Preparation and characterizations of $\mathrm{Bi}_{2} \mathrm{O}_{3}$ thin film and $\mathrm{Bi}_{2} \mathrm{O}_{2} \mathrm{Se}$ thin film}

Firstly, $1 \mathrm{~g} \mathrm{Bi}\left(\mathrm{NO}_{3}\right)_{3} \cdot 5 \mathrm{H}_{2} \mathrm{O}$ (purchased from Energy Chemical, China, 99\%) was dissolved in $10 \mathrm{~mL}\left(\mathrm{CH}_{2} \mathrm{OH}\right)_{2}$ (purchased from Sinopharm Chemical Reagent, HPLC) to form colorless and transparent solution. Secondly, the $\mathrm{Bi}\left(\mathrm{NO}_{3}\right)_{3} /\left(\mathrm{CH}_{2} \mathrm{OH}\right)_{2}$ solution was dropped onto the muscovite with fresh cleavage plane and the solution was spin-coated at a certain rotate speed $(2000 \mathrm{rpm}, 3000$ rpm etc.) for $60 \mathrm{~s}$. Then the $\mathrm{Bi}\left(\mathrm{NO}_{3}\right)_{3} /\left(\mathrm{CH}_{2} \mathrm{OH}\right)_{2}$ thin film was heated at $180{ }^{\circ} \mathrm{C}$ for a few seconds to evaporate the solvent. Finally, the $\mathrm{Bi}\left(\mathrm{NO}_{3}\right)_{3}$ thin film was placed inside a quartz tube at the center of a horizontal tubular furnace in air to obtain $\mathrm{Bi}_{2} \mathrm{O}_{3}$ thin film. The furnace was programmed to reach $480{ }^{\circ} \mathrm{C}$ with elevation rate of $\sim 8{ }^{\circ} \mathrm{C} / \mathrm{min}$ and kept for $30 \mathrm{~min}$.

As obtained the uniform $\mathrm{Bi}_{2} \mathrm{O}_{3}$ thin film was obtained, it can be transformed into $\mathrm{Bi}_{2} \mathrm{O}_{2} \mathrm{Se}$ thin film by in-situ selenization. The selenization took place in a homemade low-pressure chemical vapor deposition system (CVD) equipped with a 30$\mathrm{mm}$ diameter quartz tube inside a horizontal tubular furnace (Lindberg/Blue $\mathrm{M}$ ). The selenium pills (purchased from Alfa Aesar, 5N) and $\mathrm{Bi}_{2} \mathrm{O}_{3}$ thin film were separately located at the upstream and downstream heating zones. The selenium pills were heated to $230{ }^{\circ} \mathrm{C}$ and evaporated into gas. Then the $\mathrm{Se}_{2}$ vapor was carried to the downstream by Argon and reacted with $\mathrm{Bi}_{2} \mathrm{O}_{3}$ thin film at $500{ }^{\circ} \mathrm{C}$ to obtain $\mathrm{Bi}_{2} \mathrm{O}_{2} \mathrm{Se}$ thin film. The system pressure was kept at 400 torr.

The morphology of $\mathrm{Bi}_{2} \mathrm{O}_{3}$ and $\mathrm{Bi}_{2} \mathrm{O}_{2} \mathrm{Se}$ thin film were performed by optical microscopy (OM, Olympus DX51 microscope) and atomic force microscopy (AFM, Bruker Dimension Icon with Nanoscope V controller). The Raman spectroscopy was performed on a confocal Raman spectrograph (JY Horiba HR800) under backscattering configuration, and the laser $(633 \mathrm{~nm})$ is focused on the sample by a $100 \times$ objective lens $(\mathrm{NA}=0.9)$. The crystal structures of $\mathrm{Bi}_{2} \mathrm{O}_{3}$ and $\mathrm{Bi}_{2} \mathrm{O}_{2} \mathrm{Se}$ were verified by X-ray diffraction (XRD, Rigaku D/Max-2000 diffractometer, $\mathrm{Cu}$ $\mathrm{K} \alpha$ radiation $(\lambda=0.15406 \mathrm{~nm})$ at $40 \mathrm{kV}$ and $100 \mathrm{~mA})$. The cross-sectional STEM images were recorded using an aberration-corrected Titan Themis G2 microscope at $300 \mathrm{kV}$ with a beam current of $20 \mathrm{pA}$. The convergence semi-angle for imaging is $30 \mathrm{mrad}$, the collection semi-angles snap is 39 to $200 \mathrm{mrad}$.

\section{Device fabrication on muscovite and transfer onto flexible substrate}

The Hall-bars were fabricated directly on the insulating muscovite substrate. We first patterned the $\mathrm{Bi}_{2} \mathrm{O}_{2} \mathrm{Se}$ continuous thin film $(8 \mathrm{~nm})$ into discrete $40 \times 20 \mu \mathrm{m}^{2}$ sheets by standard photolithography techniques and wet chemical etching method reported before. Second, alignment marker arrays were predefined onto the muscovite with standard photolithography techniques. A standard electron beam lithography (EBL) process was then applied to create a polymethyl methacrylate (PMMA) mask that exposes source/drain region of Hall-bars for depositing $\mathrm{Pd} / \mathrm{Au}$ electrodes $(5 / 50 \mathrm{~nm})$ by thermal evaporation. Top-gate field- 
effect transistors (FETs) were fabricated with the same process first. The top gate dielectrics were formed through depositing $20 \mathrm{~nm} \mathrm{HfO}_{2}$ by atomic layer deposition (ALD), followed by depositing $5 / 50 \mathrm{~nm} \mathrm{Cr} / \mathrm{Au}$ as top-gate electrodes by thermal evaporation.

\section{Part II: Results and discussion}

\section{Selection of substrate and precursor for $\mathrm{Bi}_{2} \mathrm{O}_{2} \mathrm{Se}$ thin film}

Muscovite $\left(\mathrm{K}\left\{\mathrm{Al}_{2}\left[\mathrm{AlSi}_{3} \mathrm{O}_{10}\right](\mathrm{OH})_{2}\right\}\right)$ mica, which is a widely used substrate for the growth of $2 \mathrm{D}$ materials thanks to its atomically flat surface at centimeter scale, was chosen as the substrate for the growth of uniform $\mathrm{Bi}_{2} \mathrm{O}_{2} \mathrm{Se}$ thin film. As shown in Figure $\mathrm{S} 1$, the contact angle between muscovite and $\mathrm{Bi}\left(\mathrm{NO}_{3}\right)_{3} /\left(\mathrm{CH}_{2} \mathrm{OH}\right)_{2}$ solution was as small as $6^{\circ}$ (Figure $\mathrm{S} 1$ ), which suggested excellent affinity between muscovite and the solution, confirming the Bi-containing precursor superbly uniform on the muscovite.

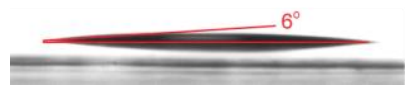

Figure S1. Contact angle test of muscovite mica and $\mathrm{Bi}\left(\mathrm{NO}_{3}\right)_{3} /\left(\mathrm{CH}_{2} \mathrm{OH}\right)_{2}$.

$\mathrm{Bi}\left(\mathrm{NO}_{3}\right)_{3} \cdot 5 \mathrm{H}_{2} \mathrm{O}$ was chosen as the precursor of $\mathrm{Bi}_{2} \mathrm{O}_{3}$ thin film, because it can decompose into $\mathrm{Bi}_{2} \mathrm{O}_{3}$ at relatively low temperature without any residue. The reaction proceeded as follows: $\mathrm{Bi}\left(\mathrm{NO}_{3}\right)_{3} \cdot 5 \mathrm{H}_{2} \mathrm{O} \rightarrow \mathrm{Bi}_{2} \mathrm{O}_{3}+\mathrm{NO}_{\mathrm{x}}+\mathrm{O}_{2}+\mathrm{H}_{2} \mathrm{O}$. According to Thermogravimetric Analysis (TGA) and Differential Scanning Calorimetry (DSC) tests (Figure S2), the difference between the mass of $\mathrm{Bi}\left(\mathrm{NO}_{3}\right)_{3} \cdot 5 \mathrm{H}_{2} \mathrm{O}$ and decomposed $\mathrm{Bi}\left(\mathrm{NO}_{3}\right)_{3} \cdot 5 \mathrm{H}_{2} \mathrm{O}$ is $51.9 \%$ derived from the DSC, which was identical to $\left[2 \mathrm{M}\left(\mathrm{Bi}\left(\mathrm{NO}_{3}\right)_{3} \cdot 5 \mathrm{H}_{2} \mathrm{O}\right)-\mathrm{M}\left(\mathrm{Bi}_{2} \mathrm{O}_{3}\right)\right] / 2 \mathrm{M}\left(\mathrm{Bi}\left(\mathrm{NO}_{3}\right)_{3} \cdot 5 \mathrm{H}_{2} \mathrm{O}\right)$ $(52 \%)$. It was indicated that $\mathrm{Bi}\left(\mathrm{NO}_{3}\right)_{3} \cdot 5 \mathrm{H}_{2} \mathrm{O}$ was decomposed completely into $\mathrm{Bi}_{2} \mathrm{O}_{3}$ at $529{ }^{\circ} \mathrm{C}$. In our experiment, in order to obtain uniform $\mathrm{Bi}_{2} \mathrm{O}_{3}$ thin film, we set the decomposition temperature at $480{ }^{\circ} \mathrm{C}$ and annealed the $\mathrm{Bi}\left(\mathrm{NO}_{3}\right)_{3}$ thin film for a long time.

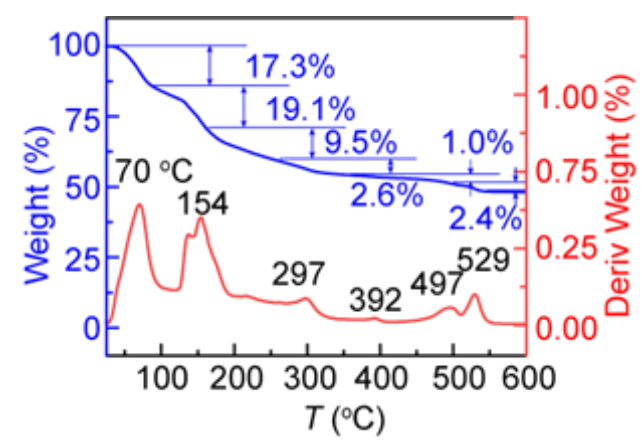

Figure S2. Thermogravimetric Analysis (TGA) and Differential Scanning Calorimetry (DSC) curves of $\mathrm{Bi}\left(\mathrm{NO}_{3}\right)_{3} \cdot 5 \mathrm{H}_{2} \mathrm{O}$

\section{Morphology and crystal structure of $\mathrm{Bi}_{2} \mathrm{O}_{3}$ thin film}



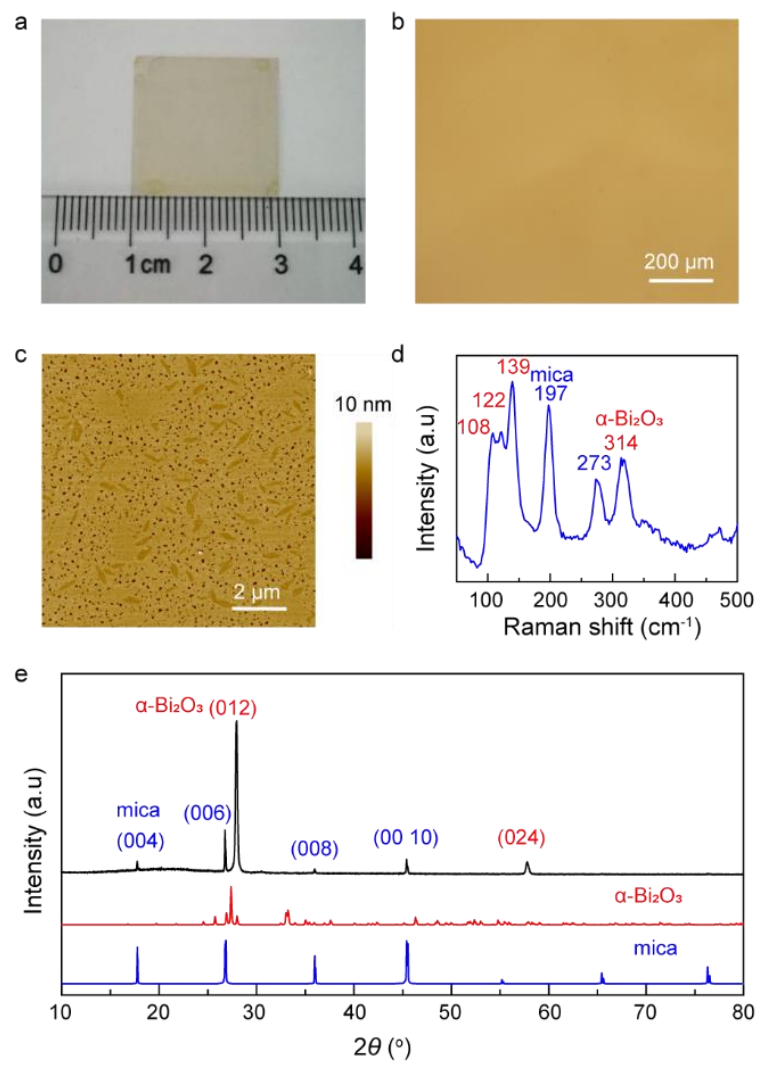

Figure S3. Morphology and structure analysis of $\mathrm{Bi}_{2} \mathrm{O}_{3}$ thin film. (a) Photograph of $\mathrm{Bi}_{2} \mathrm{O}_{3}$ thin film; (b) Optical microscopy image of $\mathrm{Bi}_{2} \mathrm{O}_{3}$ thin film with excellent uniformity; (c) Atomic force microscopy (AFM) image of $\mathrm{Bi}_{2} \mathrm{O}_{3}$ thin film; (d) Raman spectrum of $\mathrm{Bi}_{2} \mathrm{O}_{3}$ thin film showed that the $\mathrm{Bi}_{2} \mathrm{O}_{3}$ is of $\alpha$-phase; (e) XRD pattern of $\mathrm{Bi}_{2} \mathrm{O}_{3}$ thin film on mica verified the crystal structure and it is aligned to (012) crystal plane.

\section{Thickness control of $\mathrm{Bi}_{2} \mathrm{O}_{2} \mathrm{Se}$ thin film}

The thickness of $\mathrm{Bi}_{2} \mathrm{O}_{2} \mathrm{Se}$ thin film can be readily controlled by changing the rotate speed as spin-coating $\mathrm{Bi}\left(\mathrm{NO}_{3}\right)_{3} /\left(\mathrm{CH}_{2} \mathrm{OH}\right)_{2}$ solution. The morphology of $\mathrm{Bi}_{2} \mathrm{O}_{2} \mathrm{Se}$ thin films with different thickness was imaging by AFM, as shown in Figure S4. These $\mathrm{Bi}_{2} \mathrm{O}_{2} \mathrm{Se}$ thin films were uniform and continuous. 


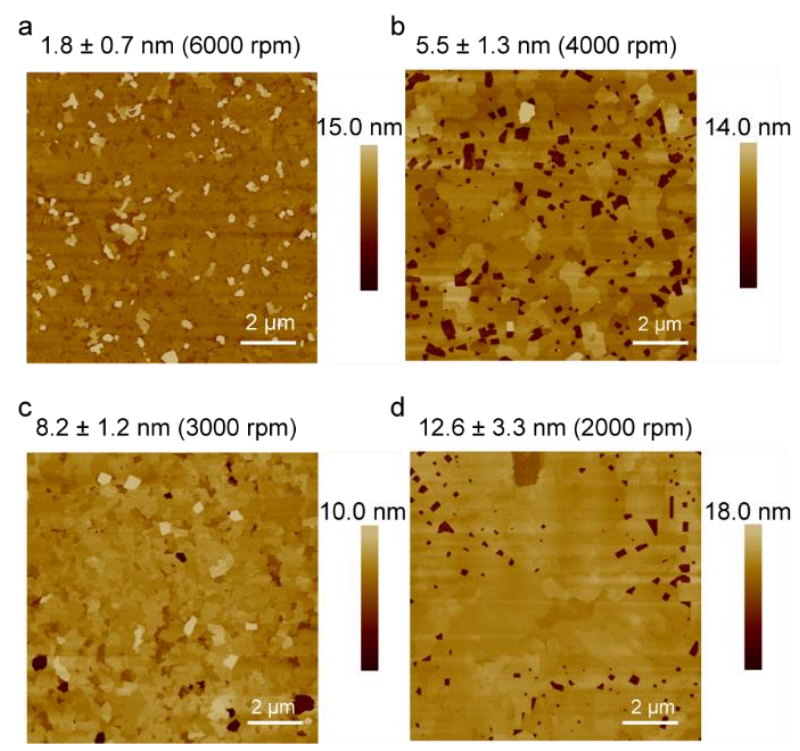

Figure S4. Morphology of $\mathrm{Bi}_{2} \mathrm{O}_{2} \mathrm{Se}$ thin films with different thicknesses

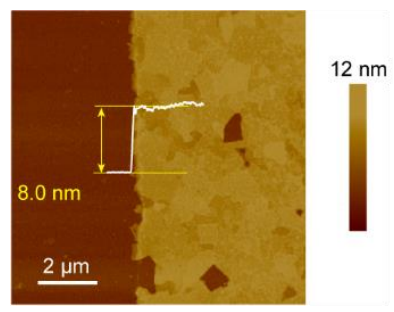

Figure S5. AFM image of $\mathrm{Bi}_{2} \mathrm{O}_{2} \mathrm{Se}$ thin film prepared at $3000 \mathrm{rpm}$, which is etched into discrete sheets by wet chemical method.

\section{Fabrication of devices on flexible substrate}

A transfer technique was implemented after device fabrication. FETs were transferred onto flexible substrate polyvinyl chloride (PVC) with assist of thermal release tape. Firstly, thermal release tape was attached to the surface of FETs on muscovite (Figure S6a). Secondly, thanks to its layer structure, thick muscovite would be cleaved leaving thin muscovite with devices attached to the thermal release tape (Figure S6b). Then the thermal release tape/devices/thin muscovite structure could be stick to PVC with double-sided tape (Figure S6c). Finally, the above-mentioned structure would be heated at $100{ }^{\circ} \mathrm{C}$ to release the thermal release tape (Figure S6d). This strategy can be expanded to other materials growing on layered hard substrates for flexible electronics. 

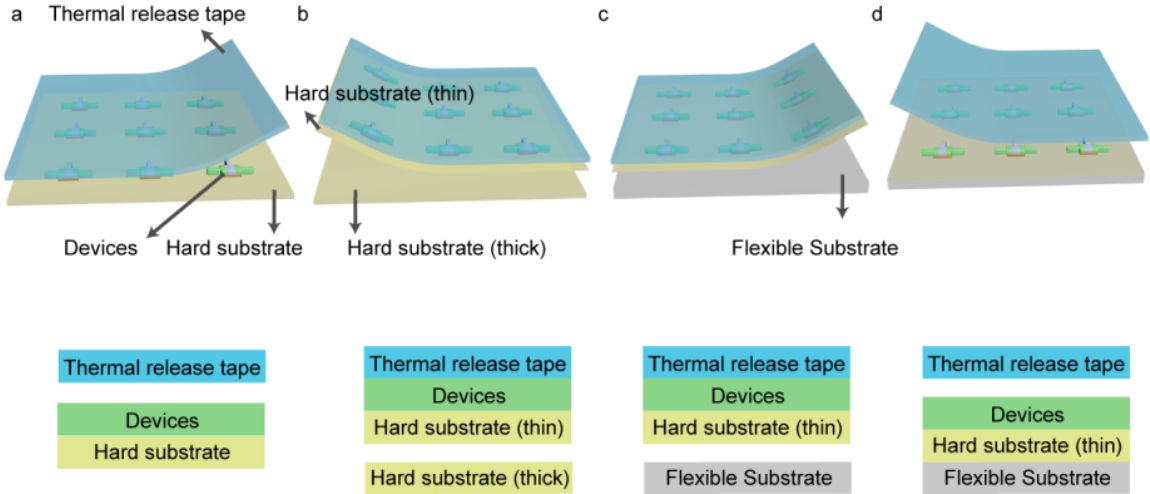

Thermal release tape

Hard substrate

Hard substrate (thick)

Flexible Substrate

Devices
Hard substrate (thin)

Flexible Substrate

Figure S6. Scheme of devices transferred onto flexible substrate 